\title{
Repeated reports to child protection Interpreting the data
}

\author{
Clare Tilbury
}

This article examines data regarding three performance indicators that cast light on child protection intake and assessment processes, when children are reported to child protection agencies because of concerns about abuse or neglect. Rates of renotification, substantiation. ard resubstantiation are examined. What do the data reveal about whether intervention is effective in kepping children safe from further hatm and whether investigative resources are targeted to priority cases? The policy implications are discussed.
Clate Tilbury

School of Social Work and Social Folicy

University of Queensland, Qld 4072

Email: ctibum@socialuq.edu.au
Perfornance measurement is a mainstay of contemporary public sector management. It involves:

- defining objectives or 'outcomes' for govemment or agency policies and programs;

- articulating the strategies, services and activities ('outputs' and 'processes') used to meet those objectives: and

- using quantitative data ('mensures' or 'indicators') to analyse "performance" (a combination of effectiveness and efficiency) on an ongoing basis (Carter, Klein \& Day 1992; SCRCSSP 2002).

Performance data on child protection are reported anmually by the Steering Committee for the Review of Commonweaith-State Service Provision (SCRCSSP) and in all States' budget papers. Unlike in the USA and England, in Australia there has been little debate about performance measurement in child protection, but that makes it no less important here in tems of its potential impact on policy and practice.

This article examines data conceming thee performance indicators that illuminate what happens at the 'front end' of the child protection process when children are reported to child protection agencies because of concens about abuse or neglect. The indicators examined ate rates of renotification, substantiation and resubstantiation. These indicators are intended to monitor whether intervention is effective in keeping children safe from further ham and whether investigative resources are appropriately targeted. What can the data vell us about performance in these areas?

\section{RECENT CHANGES IN APPROACH}

Research in the 1980 s and 1990 s caused many jurisdictions to rethink approaches to child protection. Findings from research in the UK were part of this shift in thinking:

- an explosion in the number of reports of abuse and neglect in the 1980 s caused a concentration of resources on investigation and resulted in a majority of families who were reported or investigated receiving litte or no help, even when problems were identified (Gibbons, Conroy \& Bell 1995; Packman, Randall \& Jacques 1986); 
- an increase in the level and range of support services available to help families with complex and significant needs was required, including for those families 'niltered out' of the child protection system (Gibbons, et al. 1995; Tunstill 1995);

- the 'goal keeping' mode of child protection, in which placement is seen as a last resort and the emphasis is on 'kceping children out of care', can lead to a worsening of family problems and unplanned, crisis placements for children (Packman, et al. 1986); and

- poor planning and failure to target support services causes children for whon universal services are not sufficient to miss out on help, creating a system that is 'service-led" rather than 'needs-led' (Audit Commission 1994).

In the USA, similar trends were evident. Research there called for:

a increasing the level and range of services available to families, particularly those with 'less serious' problems (Waldfogel 1998);

- the provision of family support as part of a child protection continum (Pecora, Fraser, Nelson, McCroskey \& Meezan 1995);

- a partnership approach with parents (Whittaker 1991); and

- the need to deal differently with the huge numbers of reports received and the large proportion of unsubstantiated investigations (Faver, Crawford \& Combs-Orne 1999; Waldfogel 1998).

The issues raised in this research resonated with developments in Australia (for example, Clarke 1995; Thorpe 1994; Van Soelen 1994). Most jurisdictions embarked on refoms in the 1990s to manage intake and assessment procedures (see Figure 1 for examples). The reforms involved two main areas: differential responses to notifications, reducing reliance on investigation as the first and only response by redirecting some cases to family support services; and the theory and practice of risk assessment. In practice these two areas are inter-related, because the crucial issue in introducing differential responses is the basis for deciding what response is right for what level of risk (Waidfogel 1998).

Overall, research has highlighted the deleterious effects on outcomes for children and families of concentrating resources on receiving and responding to reports of abuse and neglect th the expense of a more comprehensive approach to meeting the needs of families experiencing serious difficuly in caring for their children. Jmproving access to fanily support, particularly in the early stages of
Figure 1 Mamples of strategies to manage intake and assessment procedures

Queensland - 1992-93

- new guidelines for determining what constitutes a notification to differentiate child protection notifications from general child and family welfare intake;

- advice and referral responses for less serious notifications;

" capacity to provide brief counselling or support when statutory intervention is not warranted; and

* replacing the term 'investigation' with 'initial assessment' to better define the child protection role in contrast to the forensic/investigation role of police.

Wostern Australia - 1995-96

" new guidelines for determining what constitutes a notification to differentiate child maltreatment allegations (investigative response) from child concern reports (assessment response); and

* providing family support when statutory intervention is not warranted.

South Austraila - 1997

- new system for screening and resource fargeting involving centralised statewido intake and structured risk assessment fools to classify notifications, tailoring responses depending on the level of indicated risk

Victoria $-1998-99$

- differentiated responses to notifications according to degrees of risk and diversity of needs for clients at intake;

* a professional judgment risk assessment tool; and

m specialist family support services for 'at risk' families who do not require e protedive response.

New South Wales - 2000

- new legisiation allowing for flexibility in dealing with notifications;

- an emphasis on early support; and

- the introduction of centralised statewide intake

contact with families, is seen as essential to move policy and practice beyond 'child rescue' towards a more integrated paradigm that recognises the impact of personal, family and shructural factors effecting child abuse and neglect (Aldgate \& Hill 1995; Colton, Drury \& Willians 1995; Tonison 1999; Waldrogel 1998; Whittaker 1991).

This paper utilises perfomance indicator data to examine the picture now emerging about what is happoning at the early stages of child protection work in Australia. What can these data tell us about policy and practice? 


\section{THE INDICATORS}

\section{RENOTIFICATION RATE}

The renotification (also called re-referral) rate is the proportion of all notified cases that have been subject to a previous notification. It does not necessarily indicate that a child has been subject to further harm, but that someone was sufficiently concemed about a child to make a report that requires some sort of response from the child protection agency. This response may be limited to receiving a telephone call but may also involve recording information, checking for previous child protection history, making a referral, providing advice, obtaining information from other sources, or conducting an initial assessment or investigation. It might be posited that if an inadequate response is made to the first notification, the likelihood of an additional notification increases. Harm might not be assessed or substantiated for either notification, but a high renotification rate tends to indicate poor targeting of resources because work has to be re-done (several times over in some cases). In one of the few studies on renotification, English, Marshall, Brummel \& Ome (1999) argue that renotification is an important accountability measure because of the crucial importance of prior history in predicting future harm. A high renotification rate indicates that the screening system is not addressing cumulative harm and that families may not be receiving appropriate post-notification services. The renotification rate is time-dependant, and some renotifications result from changes of family circumstances (such as separation or re-partnering) rather than needs not being adequately assessed or addressed the first time. However the importance of considering family history in assessing risk is underscored when renotification rates are analysed over a lengthy time period.

Changes to intake procedures undertaken in the $1990 \mathrm{~s}$ caused the number of investigations and, in many cases, the number of notifications, to drop significantly in the period immediately thereafter (Iohnstone 2000). However, since 2000 , the number of notifications and investigations has started climbing again (except in Tasmania, ACT and NT) (AIHW 2002a). This can be attributed in part to extensive mandatory reporting provisions in some States. However, it is apparent from trends in some jurisdictions that a significant reason for the increase is high renotification rates.

A recent Victorian report states that in $1993-94,64 \%$ of all clients notified were first time clients, whereas in $2000-01$ only $39 \%$ were first time clients. About two-thirds of notifications in 1999-2000 involved children from families where there had been a previous notification of either the child or a sibling. In 2000-01 the average number of previous notifications was 4.2 per child (Victorian Department of Human Services 2002, pp.15-16). White not strictly comparable because of the differences in defining a notification, the trend is similar in Queensland, where in
$1993-94,65 \%$ of all children notified were first-time clients and in $2000-01$, only $56 \%$ were first-time clients. That is, over 7,000 children notified in $2000-01$ ( $44 \%$ of all children notified) were subject to a prior notification since 1984-85 when notification data were first available (Queensland Department of Families 2002). in Western Australia 'child concern reports' are not counted as notifications but in $1995-$ $96,27 \%$ of these matters were re-reported as either a child concen report or a child maltreatment allegation within 12 months, and $16 \%$ of child naltreatment allegations were renotified (Parton \& Mathews 2001). Renotification rates for other jurisdictions were not available but it would be interesting to know how widespread the trend is in Australia. High renotification rates were also found in a UK study in which only $35 \%$ of families referred for investigation were 'new' to social services (Gibbons at al. 1995).

\section{Overall, research has highlighted the deleterious effects on outcomes for children and families of concentrating resources on receiving and responding to reports of abuse and neglect at the expense of a more comprehensive approach to meeting the needs of families experiencing serious difficulty in coring for their children.}

A large proportion of noufications are dealt with by means other than investigation: $38 \%$ of notifications in NSW, $64 \%$ in Victoria, 14\% in Queensland and 48\% in South Australia received a response such as advice or referral in 2000-01 (AITWW 2002a, p.12). Surely neither these responses, nor an investigative response if that is made, are sufficiently effective if a large proportion of Tamilies are subsequently renotified. Nor are responses efficient if $61 \%$ of intake resources in Victoria and $44 \%$ in Queensland went into repeat work. This conclusion holds even if the repeat work is limited to receiving a call from a notifier and no other action is taken, because each repeat call adds up to a lot of extra work given the huge volume of renotifications.

The data paint a picture of families being reported again and again to child protection agencies because they do not receive the help they need to maintain adequate care for their children. Victoria has concluded that there are a large number of families presenting with complex and chronic problems that are not assessed as resulting in significant harm to children, but who require 'extensive support and intervention" (Victorian Department of I-iuman Services 2002, p. 14). A range of program responses has been 
introduced to address this issue. The deduction that repeat work could be avoided if the child protection agency intervened more effectively at early stages is inescapable. Instead of targeting resources, intake systems are more like temporary barricades. It may be more cost effective to provide services additional to screening, assessment, advice and referral at this point in order to prevent families being renotified. As a first step, and to understand more about the link between the adequacy of intake responses and renotification, it would help to know precisely which families are being renotified, what response was made to the previous notification and the reason for the subsequent notification.

\section{SUESTANTIATION RATE}

The substantiation rate is the proportion of finalised investigations that resulted in a substantiated outcone. It indicates whether child protection investigations are effectively targeted to those children most at risk. There are both human and financial costs if investigations are not effectively targeted (AHW 2002b). Some children may be left in harnfin situations while others are the subjects of unwarranted intrusion, which car have traumatic effects on families and undernine the chances that they will volumarily seek help with parenting (Department of Health 1995).

In Australia there are significant variations in practice between jurisdictions in relation to counting both rnalised investigations and suostantiated outcomes, so data need to be carefully interpreted and comparability is limited (AHW 2002 b). In $2000-01$ reported substantiation rates for New South Wales, South Australia, Tasmania and the ACT were around $38 \%$, the Northern Tetritory was $46 \%$, Western Australia $49 \%$, Victoria $59 \%$ and Queensiand $68 \%$ (SCRCSSP 2002, p. 807).

Delemining the outcone of an investigation involves a combination of sensicivity, or predicting harm accurately (true positives), and specificity, or predicting no ham accurately (true negatives). There is a margin of ertor in all risk asscssment, resulting in false positives and false negatives. Statistically, the lower the base rate or prevalence of abuse, the greater are the limitations on improving predictions. A low threshold ('casting the net too wide') produces a bigh tate of false positives meaning unwarranted intrusion on families and a waste of scarce resources. But conversely and necessarily, raising the threshold increases false negatives - not identifying serious cases of abuse (Munro 1999). So while a high substantiation rate may indicate that the decision to investigate was the right decision and resources were not expended on investigating where children were not at risk, if it is 'too high', it might be that serious cases were missed. Following these assumptions, and looking at the outlier jurisclictions, if only $38 \%$ of the cases investigated were substantiated, perhaps too many families were unnecessarily investigated, whereas a $68 \%$ substantiation rate could indicate a very high threshold for substantiating ham. But to determine the overall efficacy of targeting strategies these data should be used to prompt further analysis rather than be considered deñnitively (SCRCSSP 2002). The substantiation rati only indicates how investigations are targeted and does not relate to the accuracy of assessments, or whether harm or risk would have been identified for notifications that were not investigated.

\section{The deduction that repeat work could be avoided if the child protection agency intervened more effectively at early stages is inescapable.}

\section{RESUGSTANTIATION RATE}

The resubstantiation (also called re-abuse or recurrence) rate is the proportion of al? children for whom ham is substantiated within a time period who are then subject to a further substantiation. it indicates whether the child protection system has been effective in keeping a child saf̂e from further ham. The rationale for the indicator is that if a child protection agency has assessed a child as having been. harmed or at risk of ham, it is expected to intervene appropriately to ensure that the child is not hamed again. Some resubstantiation may be expected, such as that resulting from disclosure by a child of ham that occurred previously or that resulting from changes in the family that are outside the control or knowledge of the agency (SCRCSSP 2002). But a high level of resubstantiation suggests intervention is not effective in either bringing about the required changes in the child's family situation or making a safe altemative plan for the child's care.

A study of $1994-95$ data from len USA states (F)uke, Yuan \& Edwards 1999) found these consistent re-abuse patterns:

- neglect is the most likely form of abuse to recur;

- re-abuse is more likely with younger children;

- re-abuse is associated with the provision of postintervention services; and

* multipie re-abuse places children most at risk compared with one recurrence or no recurrence.

These findings are consistent with the research that cautions against 'incident based ' risk assessment because children are most at risk from ongoing patterns of poor parenting (Department of Health 1995). There may be a tendency to take more decisive action in relation to physical and sexual 
abuse (a specific incident for which 'evidence' is clearer for court), making neglect and emotional abuse (when ham is cumulative and often results from a history of inactions rather than incidents) more likely to be renotified (Victorian Department of Human Services 2002).

There are various methods of counting resubstantiation. (For a discussion of these issues see Fluke et al. 1999; Poertner; McDonaid \& Murray 2000.) Most counting rules for the indicator limit the time period for counting resubstantiation to deal with the probiem of resubstantiation occurring due to changes of circumstances over time, rather than inadequate intervention. Fluke et al. (1999, p.640) found that most reabuse occurred in the six months after case closure and the relative hazard of recurrence declines as the observation period increases'. Perversely, resubstantiation rates may be higher if the agency actively follows up and keeps the case open longer, because any resubstantiation is more likely to be detected and recorded. If cases arc closed early, the chances of renotification may be smaller (Fluke et al. 1999). Studies in Britain found that most re-abuse oceurred within two years of registration, and that the te-abuse rate for severe cases (those requiring medical attention) was much lower than the rate for all cases (Department of Health 1995).

\section{... the business of delivering an effective and efficient child protection system is an ongoing pesearch and development process, in which questions about how to manage front end work are likely to be ever present.}

In Australia, resubstantiation rates within twelve months for 1999-2000 were reported as: NSW 10.2\%; Queensland $22.6 \%$; Victoria $14.0 \%$; WA $10.5 \%$; SA $23.9 \%$; ACT $17.9 \%$; Tasmania $16.5 \%$ (SCRCSSP 2002, p.802). Benchmarking resubstantiation rates with reference to performance in other jurisdictions is difficult because of legislative, policy and practice differences about what constitutes 'substantiation'. Poertner et al. (2000) found widely varying rates of recursence reported in USA studies for this reason.

There are possible problems in using resubstantiation as an indicator of safery. Given the distress and disruption that removal from home might cause for a child, and the emphasis on working with families to improve their functioning, children are only renoved when this is the best means of securing their protection. Inherently, keeping a child at home carries an increased risk of re-abuse. A level of resubstantiation does not necessarily mean that more intrusive methods of protection are warranted. Evidence about the effects of maltreatment shows that with the exception of severe assaults and some sexual abuse, longterm difficulties for children seldom follow from a single abusive event:

for the majority of cases, the need of the child and fanily is more important than the abuse ... the general family context is more important than any abusive cvent within it (Department of Health 1995 , p. 54 ).

Resubstantiation rates may be insensitive to improvements in the care of children between the first notification and an isolated recurrence.

\section{DISCUSSION: IMPLICATIONS FOR POLICY}

In summary, a high renolification rate indicates inefficient use of resources and ineffective responses made to families at inlake. A very low substantiation rate indicates poor targeting of investigations. A very high substantiation rate indicates serious cases are possibly being screened out at intake. $A$ high resubstantiation rate indicates agencies are ineffective in achieving a key outcome of safely from futher ham for children. Despite the steps taken by jurisdictions during the 1990 s to target resources, the numbers of notifications and investigations are still rising. This shows there are no simple answers: the business of delivering an effective and efficient child protection system is an ongoing research and development process, in which questions about how to manage front end work are likely to be ever present.

Improving the consistency and accuracy of risk asscsment and introducing differential responses are of limited benefft without effective intervention to reduce risk. Referrals for family support' will only "work" if the services have the capacity and skills to effectively respond to the needs of families referted to them. At a minimum this requires a shared understanding between the statutory agency and the family support service about why the family is being referred (a common assessment framework), and a case management approach in which family needs are assessed and interventions are planned, executed and monitored according to the unique needs of the family (rather than detemined by what is available). A study by English, Wingard, Marshall, Ome \& Ome (2000) compared notified families who were referred to community-based family support with those who received a "low level investigative response" involving record checks and discussion with other professionals (that is, no contact with the family). Most families in both groups were not renotified. For those who were, while there was a significantly lower renotification rate at six months for those referred to family support, the difference had diminished at twelve months, providing support for the notion that sustained ongoing assistance is 
required for many families. The study concluded that the primary issues in preventing renotification are:

(1) the parent recognising there is a problem, and

(2) parental co-operation with services.

It cannot be assumed that services will effectively engage with low risk tamilies, or that services will adequately address family needs so as to reduce renotification. These are crucial areas for further research and practice development.

Despite policy thetoric and the evidence that it is essential, family support remains marginalised in practice. This is related to media coverage of child protection and child deaths inquiries, pressure on frontine workers to adopt a forensic approach, and the consequent narrowing of assessments to focus on safety at the expense of broader needs - all manifestations of the 'risk society' in which trust in science and expert knowledge is undermined, and uncertainty and doubt about the future lad to a societal focus on risk and risk management (Parton, Thope \& Wattam 1997). Including family support in the child protection perfomance tneasurement efrort may help to contain this marginalisation. Within manageralist approaches to govemment, reporting on indicators potentially shapes policy action, making some areas of work important and others invisible. It is essential to develop indicators that reflect a broader policy agenda than narrow 'child rescue' franeworks, congruent with research about improving outcomes for children and families (Tilbury 2002). Most family support work remains unrecorded, unnoticed and therefore undervalued, and perfomance measurement provides a means to demonstrate the contribution of family support to the safety and well-being of chidden. There are criticisms about using administrative data on the grounds that it is reductionist, inaccurate, or some aspects of practice are not quantifiable. While these criticisms have some weight, most child protection data sets are fairly large-scalc and provided they are carefully interpreted, data can be useful to ask policy-relevant questions and improve practice. This seems preferable to relying on partialised, anecdotal accounts from one stakeholder or another.

It is particularly important to use available data while improving the knowlecige base in child protcction, because millions of decisions are being made about child protection every day with little or no empirical support (English et al 1999, p.298)

The point of using perfomance indicators is not to make definitive judgments about performance but to facilitate an open and reflective approach, bringing more clarity to how problems are understood and therefore where to look for solutions.
However, the complexity of measuring family support is acknowledged. A key threshold issue for family support research and practice is definitional clarity. Family support is ofen defined very broadly (see AIHW 2001 for the scope of family support services in Australia). In order to better integrate family support with child protection services, increased knowledge and understanding are required about who gets help, why, and for how long - and the corollary, who is missing out? (Little 1999).

The three indicators discussed in this paper do not represent the full story about what is happening at the early stages of child protection work, and there is much unknown about these processes. But the more data are reported and their meaning analysed, the more direction is provided for the questions and actions to pursue next - such as investigating whether repeated referrals are the result of inadequate initial response or whether there are some other processes at work, and the types of services actualy provided to families (if any) from differential responses, and their impact on child safety and well-being.

\section{CONCLUSION}

The data on renotification, substantiation and re-abuse shows that the problens of concentrating resources on investigation and filtering at-risk families out without providing services are still present. More attention is required, at multiple points along the child protection process, to actually helping famities who have serious difficulties in caring fon children.

This, surely, is not a surprise. Fanily support is intended to prevent family problems from worsening and to curtail risk. The idea of prevention is based on the idea of cause and effect, reliant on our capacity to predict and intervene. But there are real limits to predictive capabilities in child protection (Murro 1999), in which complexity and uncertainty are inherent. As demand increases and the tationing of services becomes more important, the impulse to risk assessment, categorisation and prioritisation is increased. Then, as the sophistication of risk assessment improves, we uncover problems we didn't know about before "and about which we are more precisely uncertain" (Freman 1999, p.240). The complexity of the issues is understood at a deeper level, and so the prevention system is faced with more problems to solve. Freeman (1999) describes this as the 'recursive politics' of prevention: "prevention policy appears self-propelling, constantly in need of renewal' (p.240). The data presented in this articie indicate that a renewed commitment to family support in Australian child protection systens is wararited. 


\section{REFERENCES}

Aldgate, J, \& Hill, M. (1995) 'Child welfare in the United Kingdom', Children and Youth Services Review, 17,5/6, 575-597.

Audit Commission (1994) Seen But Not Heard, HMSO, London.

Australian Institute of Health and Welfare (AJHW) (2001) Family support senvices in Australia 2000, Australian instimte of Health and Welfare, Canberra.

Australian Institute of Health and Welfare (AIHW) (2002a) Child Protection Australia 2000-01, Australian Institute of Health and Welầre, Canberrá.

Australian Institute of $\mathrm{H}$ ealth and Welfare (AIHW) (2002b) Guidelines for Interpretation of Child Protection and Out-of-Hone Care Performance Inaicators, Ausiralian lnstitute of Healuh and Welfare Canbera. www.aihw.gov,au/childyouth/childprotection/index, htm]

Carter, N., Klein, R. \& Day P. (1992) How organisations measure stacess: the wise of performance indicators in government, Roulledge, London.

Clark, R. (1995) 'Child protection services in Victoria', Fomily Matters, 40, $22-23$.

Colton, M. Drury, C. \& Williams, M. (1995) Children in Need: Fanily support under the Children Act 1989, Avebury, Aldershot.

Department of Health (1995) Child Protection: Messages from Research, HMSO, London.

English, D., Marshall, D., Brummel, S. \& Orme, M. (1999) 'Characteristics of repeated referrals to child protective services in Washington State", Child Maltratment, 4, 4, $297-307$.

English, D., Wingard, T., Marshall, D., Onme, M. \& Orme, A. (2000) "Altemative responses lo child protective services: emerging issues and concerns', Child Abuse and Neglect, 24, 3, 375-388.

Faver, C.A., Crawford, S.L. d Combs-Ome, T. (1999) Services for child malireatmerit: Challenges for rescarch and practice? Childen and Youh Services Reviews, 21, 2, 89-109.

Flukc, J.D, Yuan, Y-Y.T \& Edwards, M. (1999) 'Recustence of malteatment: an application of the national child abuse and neglect data system", Chitd Abuse and Neglect, 23, 7, 633-650.

Freeman, R. (1999) Recursive politics: prevention, modernity and social systems", Children and Society, 13, 232-24 I.

Gibons, J., Conroy S. \& Bell, C. (1995) Operating the chitd protedion system, TMMSO, London.

Johnstonc, H. (2000) The national child protection data collection. What does ien years worth of dar tell ws?, paper presented at the $7^{\text {th }}$ Australian Institutc of t:amily Studies Conference, Sydney.

Little, M. (1999) 'Prevention and early intervention with chitdren in need: Definitions, principles and examples of good practice? Children and Sociery, 13, 304-316

Munro, E. (1999) 'Protecting children in an anxious sociely', Fealth, Risk and Society, I, 1, 117-127.

Packman, I., Randall, J. \& Jacques, N. (1986) Who Needs Care? Social Fork Decisions about Chidren, Basil Blackwell, Oxford.

Parton, N., Thomp, D. \& Wattam, C. (1997) Child Protection: Risk and the Moral Order, Macmillan, Basingstoke UK.

Parton, N. \& Mathews R. (2001) New directions in child protection and family support in Western Australia: a policy initiative to re-focus child welfare practice', Child and Family Social Work, 6, 97-113.

Pecora, P.J., Fraser, M.W., Nelson, K., McCroskey, . \& Meczan, W. (1995) Evaluating Fantily-Based Services, Aldine de Gruyter, New York.

Poertner, 3., McDonaid, T.P. \& Muray, C. (2000) Child welfarc outcomes revisited, Children and Youth Services Review, 22, 9/10, $789-810$.

Queensiand Department of Families (2002) Statistical Services Unit, 4 October 2002.

Stering Committee lor the Review of Commonwealth/State Service Provision (SCRCSSP) (2002) Report on Governmen Services 2001, Ausinfo, Canberra.
Thorpe, D. (1994). Evaluating Child Protection, Open Universily Press, Buckingham.

Tilbury, C. (2002) 'Performance measurement in child protection?" Australian Social Work, 55, 2, 136-146.

Tomison, A.M. (1999) Ensuring the protection of children: the role of child protection services in the identification, assessment and treatment of maltreated children, paper presented at NSW Department of Community Services 'Entry paramelers to clith and family services' workshop, 22-23 March 1999, Sydney.

Tunstill, J. (1995) "The concept of children in need: The answer or the problem for tamily support?' Children and Youth Senvices Revien', 17, 5/6, 651-664,

Van Socicn, S. (1994) Future Directions in Child Protection. unpublished papen presented at 'Child Protection in Context' conference, 22 November 1994, ni.j.

Victorian Department of Human Services (2002) An Integlated Strategy for Child Protection and Placenent Sevices, Community Care Division, DHS, Melboume.

Waldrogel, 1. (1998) "Rethinking the paradigm for child protection", The Future of Children, 8, 1, 104-179.

Whittaker, I K. (1991) "The leadership chalienge in tamily-based services: policy, practice and research" Families in Soctory, May, $294-300$. 